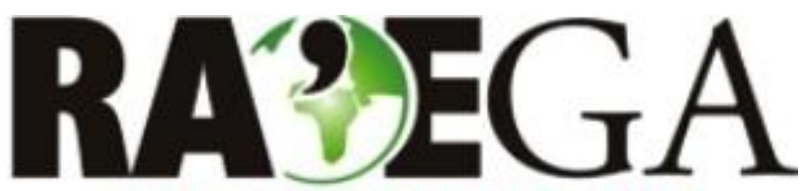

O ESPACO GEOGRÁFICO EM ANÁLISE

\title{
DINÂMICA ESPACIAL E TEMPORAL DO USO DO SOLO E ÍNDICE DE VEGETAÇÃO POR DIFERENÇA NORMALIZADA (NDVI) EM SETOR DE CABECEIRA DO RIO SÃO LOURENÇO, CAMPO VERDE, MT.
}

\section{SPATIAL AND TEMPORAL DYNAMICS OF LAND USE AND NORMALIZED DIFFERENCE VEGETATION INDEX (NDVI) SECTOR IN BEDSIDE OF SÃO LOURENÇO RIVER, CAMPO VERDE, MT.}

\author{
Anny Keli Aparecida Alves Cândido \\ Doutoranda em Saneamento Ambiental e Recursos Hídricos. Universidade Federal de Mato Grosso \\ do Sul (UFMS) \\ Faculdade das Engenharias, Arquitetura e Urbanismo e Geografia (FAENG) \\ Campo Grande, MS \\ e-mail: anny.keli@hotmail.com
}

Normandes Matos da Silva Professor da Universidade Federal de Mato Grosso (UFMT) Instituto de Ciências Agrárias e Tecnológicas (ICAT) Rondonópolis, MT e-mail: normandes@ufmt.br

Domingos Sávio Barbosa Professor da Universidade Federal de Mato Grosso (UFMT) Campus Universitário de Rondonópolis Rondonópolis, MT e-mail:domsavis@hotmail.com

\section{Resumo}

Avaliou-se a dinâmica espacial e temporal do uso do solo na microbacia que contém a nascente do Rio São Lourenço, situada no bioma Cerrado. Foram utilizadas imagens orbitais obtidas pelo sensor Mapeador Temático (TM) do Landsat 5, referentes à órbita/ponto 226/71 dos anos de 1985, 1997 e 2011, com resolução espacial de 30 


\title{
DINÂMICA ESPACIAL E TEMPORAL DO USO DO SOLO E ÍNDICE DE VEGETAÇÃO POR DIFERENÇA NORMALIZADA (NDVI) EM SETOR DE CABECEIRA DO RIO SÃO LOURENÇO, CAMPO VERDE, MT
}

metros, compreendendo um período de 26 anos. O mapa de uso das terras foi gerado a partir de classificação supervisionada, utilizando o algoritmo Máximo Verossimilhança. O Índice de vegetação por diferença normalizada (NDVI) foi gerado a partir das bandas 4 e 3 correspondentes ao infravermelho próximo e ao vermelho, respectivamente. Verificou-se que mais de $78 \%$ da área da microbacia é destinada à agricultura. A classe floresta aumentou no decorrer dos anos analisados, fato este explicado pelo plantio de floresta de eucalipto, no setor norte da microbacia. O NDVI evidenciou áreas que estavam com pouca biomassa vegetal, diferenciando-as das áreas com cobertura vegetal densa. Considerando o NDVI de uma área em processo de recuperação ambiental, denominada de unidade demonstrativa de restauração ecológica, observouse que com nove meses de implantação, a mesma ainda não apresenta resposta espectral semelhante à mata ciliar adjacente. As matas ciliares da microbacia representam potenciais corredores de dispersão de fluxo biológico, que conectam áreas de planalto situadas no bioma Cerrado à planície sedimentar do Pantanal situada no sudoeste de Mato Grosso. A pesquisa fornece subsídios para a adequação ambiental das propriedades rurais junto à legislação ambiental pertinente.

Palavras-chave: Planejamento Ambiental, Recuperação de Áreas Degradadas, Sensoriamento remoto.

\begin{abstract}
There was an analysis of spatial and temporal dynamics of land use over a period of 26 years in the watershed located in headwaters of São Lourenço River, located in the Cerrado biome. The images used to conduct the study were obtained by the sensor Thematic Mapper (TM) Landsat 5, referred to path/row 226/71 of the years 1985, 1997 and 2011, with a spatial resolution of 30 meters. The land use map was generated from supervised classification using Maximum Likelihood algorithm. The Normalized Difference Vegetation Index (NDVI) was generated from 4 and 3 bands corresponding to the near infrared and red, respectively. It was verified that over $78 \%$ of the watershed area is intended to agriculture. The forest class increased over the years analyzed, which is explained by the plantation of eucalyptus forest in the northern part of the watershed. The NDVI showed areas with little biomass, differing them from areas with dense vegetation cover. By analyzing the NDVI of an area in the process of environmental recovery, called ecological restoration demonstration unit, it was noted that in nine months of implantation, the area still does not show spectral features that are similar to the riparian forest. The riparian forests of the watershed represent potential dispersal corridors of biological flow, which connect the upland areas located in the Cerrado to the lowlands of Pantanal, located in the southwest of Mato Grosso. The research provides grant for environmental adaptation of the rural properties along with the relevant environmental legislation.
\end{abstract}

Keywords: Environmental Planning; Recovery of Degraded Areas; Remote Sensing. 


\section{INTRODUÇÃO}

A biodiversidade do Cerrado vem sendo deteriorada por conta da degradação progressiva de seus recursos naturais, promovida pela dispersão de espécies exóticas e invasoras, pelo uso de técnicas inadequadas de manejo do solo, incluindo a expansão da agropecuária sobre ambientes naturalmente frágeis, como áreas de preservação permanente. $A$ isso, soma-se a baixa atenção que este bioma recebe em termos de políticas públicas, quando se compara à Amazônia (KLINK; MACHADO, 2005, p. 711).

Dados governamentais informam que em 2009, o Estado de Mato Grosso já apresentava um terço de seu território composto por áreas degradadas ou em processo de degradação progressiva (MATO GROSSO, 2009, p.3). Nas sub-bacias dos rios São Lourenço e Vermelho, região sudeste do Estado, existiam em 2009 em torno de 20 microbacias, com 25 mil hectares de áreas degradadas (46\% da sua área total), incluindo 86 voçorocas e 61 nascentes deterioradas (RHOLING; SILVA, 2012, p.43).

O referido Estado regulamentou nos fins da década de 90, o primeiro sistema estadual de licenciamento ambiental de propriedades rurais na Amazônia Legal, denominado de Sistema de Licenciamento Ambiental de Propriedades Rurais (SLAPR). Estudos indicam que o programa SLAPR foi bem sucedido em legalizar desmatamentos, porém não reduziu os desmatamentos neste período (AZEVEDO; SAITO, 2013, p. 116 e FATORELLI; MERTENS, 2010, p.407).

A pouca eficiência dos resultados de políticas de conservação do Cerrado, se traduz em reduzido monitoramento sistemático de áreas submetidas à intensa pressão antrópica, o que dificulta o conhecimento sobre os inúmeros processos e fatores envolvidos na perturbação, degradação, recolonização e restabelecimento dos ecossistemas (KLINK; MACHADO, 2005, p. 711).

A determinação da dinâmica espaço-temporal do uso e ocupação das terras e a utilização de índices de vegetação, obtidos a partir do processamento de imagens de satélite, representa importante ferramenta de planejamento para estudos relacionados à identificação de áreas prioritárias para a conservação da 
biodiversidade, bem como para recuperação de ambientes degradados, dentre outros aspectos (CHAVES et al. 2010, p. 715; FERNANDES et al. 2008, p.1363).

O estudo avaliou a dinâmica espacial e temporal do uso e ocupação das terras, a fim de compreender as alterações ambientais na área pesquisada e gerar dados que subsidiem ações de recuperação de áreas degradadas no setor de cabeceira do rio São Lourenço, que nasce no bioma Cerrado e é um importante formador da planície pantaneira.

\section{MATERIAIS E MÉTODOS}

\section{1. Área de estudo}

O município de Campo Verde está situado no sudeste do estado de Mato Grosso (Figura 01), ocupando 4.782,116 km². A população aproximada em 2013 foi de 35.578 habitantes. A economia baseia-se na agricultura com cultivo de grãos (soja, milho) e algodão. O município também apresenta importante produção de hortaliças, que abastece aproximadamente $40 \%$, dos municípios de Cuiabá, Várzea Grande e Rondonópolis, os mais populosos de Mato Grosso (CAMPO VERDE, 2014, p.1).

O estudo foi realizado na cabeceira do Rio São Lourenço, que é denominada localmente como Córrego dos Compadres, estando localizado em área de agricultura intensiva altamente mecanizada. O clima é do tipo tropical quente e subúmido, com quatro meses de seca sendo eles de maio à agosto (MATO GROSSO, 2012). De acordo com Checoli (2012, p.46) os solos predominantes na área de estudo são o Latossolos Vermelho e Vermelho-Amarelo, sendo que a precipitação média anual é de $1.750 \mathrm{~mm}$, com intensidade máxima em dezembro, janeiro e fevereiro. IBGE (2014, p.1) informa que a temperatura média anual no município é de $22^{\circ} \mathrm{C}$, com relevo predominantemente plano, equivalente a $70 \%$ do território, com $28 \%$ de relevo ondulado e $2 \%$ de relevo montanhoso. O município é banhado pelo Rio das Mortes, Rio Aricá Mirim, Rio Cumbica, Rio Roncador, Rio Ximbica, Rio Galheiros, Rio da Casca e um dos principais, o Rio São Lourenço, que deságua no Pantanal Mato-Grossense. A vegetação nativa está restrita a poucos 
remanescentes, sendo representada por fisionomias vegetais do cerrado lato sensu, que podem variar de formações campestres a florestais (IBGE, 2004, p.1).

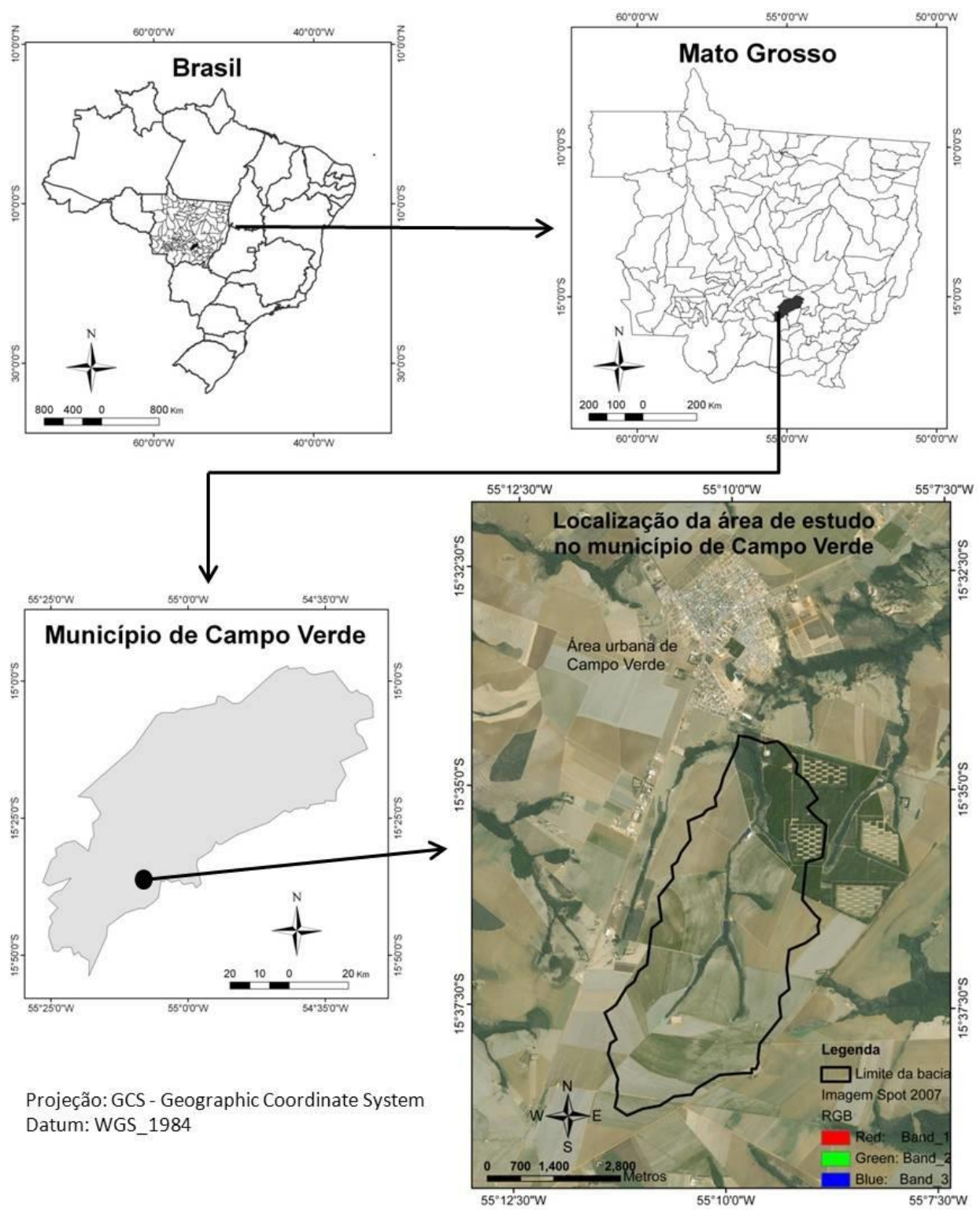

Figura 1: Localização da microbacia que contém a nascente do Rio São Lourenço em campo VerdeMT

Fonte: Mapa político do Brasil com unidades da federação (IBGE, 2013), imagem SPOT do ano de 2007 (SEMA, 2010) e limite da microbacia (SEMA, 2011). Org. dos autores

\subsection{Mapeamento do uso e ocupação do solo}

O limite da microbacia da cabeceira do Rio São Lourenço foi obtido na página eletrônica da Secretaria de Meio ambiente de Mato Grosso. Foram utilizadas 
imagens derivadas do sensor Mapeador Temático (TM) do satélite Landsat 5, referentes ao ponto 226 e a órbita 71 dos anos de 1985 (23/10/1985), 1997 (08/10/1997) e 2011 (29/09/2011). As imagens possuem resolução espacial de 30 metros e foram adquiridas gratuitamente junto à Divisão de Geração de Imagens (DGl) do Instituto Nacional de Pesquisas Espaciais (INPE), a partir da página eletrônica da referida instituição. A atribuição de parâmetros cartográficos nas imagens, visando a sua correção geométrica e posterior processamento, teve como referência a base GLCF (Global Land Cover Facility) disponível na página eletrônica: http://www.landcover.org/index.shtml. A projeção selecionada foi a UTM, Zona 21S, datum SAD-69.

Adotou-se o método de classificação supervisionado, devido ao conhecimento prévio da área de estudo. A classificação foi realizada no Sistema de Informações Geográficas (SIG) ArcGis $\AA^{\circ}$, versão 9.3.1, a partir de imagens Landsat 5 TM. Foram utilizadas cinco bandas: 2, 3, 4, 5 e 7 e o algoritmo adotado foi o Máximo Verossimilhança, utilizado por produzir resultados eficientes e ser amplamente empregado em trabalhos dessa natureza. Esse algoritmo classifica os pixels desconhecidos de acordo com a seguinte fórmula:

$$
P c=\left[-0,5 \log _{e}\left(\operatorname{Det}\left(V_{c}\right)\right)\right]-\left[0,5(X-M c)^{\top}(V c)^{-1}(X-M c)\right]
$$

Onde: $\mathrm{X}=$ vetor de medidas dos pixels desconhecidos; $\mathrm{P} c=$ probabilidade de o vetor $\mathrm{X}$ ser assinalado na classe $\mathrm{c}$; $\mathrm{V} c=$ matriz de covariância da classe $\mathrm{c}$ contemplando todas as bandas $(\mathrm{K}, \ldots, \mathrm{L}) ;$ Det $(\mathrm{V} c)=$ determinante da matriz de covariância $\mathrm{V} c$; $\mathrm{M} c=$ vetor das médias para cada classe $c$; e $\mathrm{T}=$ matriz transposta (SANTOS et al. 2010, p.102).

As classes adotadas que compõem a legenda dos mapas foram baseadas no trabalho de Loebmann et al. (2012, p.5), constante em documento técnico da Embrapa. No programa ArcGis ${ }^{\circledR}$ 9.3.1 (ESRI, 2010), as amostras para classificação das imagens de satélite, foram adquiridas contemplando classes de interesse dentro da área de estudo. Para a aquisição das amostras, foi criado um arquivo no formato shapefile que foi sobreposto à imagem de satélite que foi classificada. Posteriormente, ativou-se o modo de edição da camada (layer) e amostras em forma 
de polígonos foram coletadas para as imagens Landsat 5 TM (1985, 1997 e 2011). Após isso, criaram-se assinaturas espectrais a partir das amostras, procedendo posteriormente à classificação supervisionada.

A pesquisa adotou as seguintes classes: Vegetação Florestal, Vegetação Herbáceo-arbustiva, Cultura de período implantação, Cultura de fase de crescimento, Corpos d'água e Vegetação Graminosa. Posteriormente, o arquivo de classificação gerado no formato matricial foi convertido para o formato vetorial, para cálculo da área pertencente a cada classe.

Considerou-se cultura no período de implantação, o solo exposto sendo preparado para o cultivo sem qualquer tipo de cobertura vegetal e na fase de plântula, onde a vegetação não cobre totalmente o solo e está com baixa atividade fotossintética. Já a classe cultura em fase de crescimento, possui maior atividade fotossintética e solo coberto pela cultura. Nas imagens Landsat (composição colorida 4R, 5G e 3B) essas classes aparecem com tons avermelhados a magenta e textura lisa (cultura em fase de implantação) e verde claro com textura lisa (cultura em fase de crescimento). A classe denominada vegetação florestal, apresentava ambiente com formação densa e predomínio de arvores, sendo que essas áreas nas imagens Landsat apresentavam coloração verde escura e textura rugosa. A classe vegetação herbáceo-arbustiva enquadra espécies arbustivas, que na imagem aparecem com coloração mesclada entre as cores verde e vermelha e textura menos rugosa. A Classe vegetação graminosa é composta por espécies que apresentam menor quantidade de material lenhoso, não utilizadas ou não desejáveis nos cultivos agrícolas, possui textura pouco rugosa, coloração esverdeada/avermelhada, onde há predomínio de gramíneas (LOEBMANN et al., 2012, p.8) (Tabela 01).

A composição de bandas utilizada permitiu diferenciar com êxito as classes de cobertura do solo adotada. Para a realização da conferência terrestre foram utilizadas imagens históricas de alta resolução espacial presentes na plataforma Google Earth® (Google, 2012) e imagens aéreas com resolução espacial de $10 \mathrm{~cm}$ 
obtidas por Veículo Aéreo Não Tripulado (VANT) em Julho de 2011, além de conhecimento prévio da área de estudo por meio de campanhas de campo.

Tabela 01: Características visuais das classes mapeadas nas imagens Landsat TM5 na composição de bandas RGB 4-5-3.

\begin{tabular}{lll}
\hline Vegetação Florestal & Cultura em fase de implantação \\
Vegetação Herbáceo-arbustiva & Cultura em fase de crescimento \\
Vegetação Graminosa & Corpo Hídrico \\
\hline
\end{tabular}

\section{3. Índice de Vegetação por Diferença Normalizada (NDVI)}

Para gerar o Índice de Vegetação por Diferença Normalizada (NDVI), foi feita correção atmosférica com as sete bandas do satélite Landsat 5TM (anos de 1985, 1997 e 2011), por meio do algoritmo ATCOR2 do programa PCI Geomática 9.1 (PCl, 2003). No mesmo software a imagem foi georreferenciada e o NDVI foi calculado a partir da ferramenta raster calculator, utilizando as bandas 3 e 4 que correspondem respectivamente a região do vermelho do espectro eletromagnético e ao infravermelho próximo. O Índice de Vegetação por Diferença Normalizada (NDVI) foi obtido a partir da equação proposta por Rouse et al. (1973) apud Ponzoni e Shimabukuro (2010, p.82).

$$
\mathrm{NDVI}=(\mathrm{IVP}-\mathrm{V}) /(\mathrm{IVP}+\mathrm{V})
$$

Onde: IVP é a refletância no infravermelho próximo $(0,75-0,90 \mu \mathrm{m})$; V é a refletância no vermelho. $(0,63-0,70 \mu \mathrm{m})$.

A microbacia estudada possui áreas que estão em fase de regularização ambiental, a partir da recuperação de área de preservação permanente degradada. A recuperação é viabilizada por meio de experimentos de campo com foco em práticas de nucleação (REIS, 2010, p.245 e CHECOLI, 2012, p.31). Esta área foi denominada de unidade demonstrativa de restauração ecológica (UDRE). Para analisar o NDVI em um dos experimentos, foi feito a vetorização dos seus limites, a partir de imagem aérea, com resolução espacial de $10 \mathrm{~cm}$, obtida por meio de câmera com resolução de 10 Mega pixels com GPS, tendo composição RGB 
convencional. Essas imagens foram obtidas por meio de veículo aéreo não tripulado (VANT - Tiriba), em missões realizadas em junho de 2011 e novembro de 2013. O polígono gerado sobre as imagens aéreas foi sobreposto ao resultado do NDVI (imagens Landsat) referente aos três anos analisados. Considerando que a área da UDRE é menor que um hectare, e as imagens Landsat utilizadas apresentarem resolução espacial de 30 metros, coletaram-se três pixels dentro do limite da UDRE. Os valores desses pixels foram anotados para cálculo da média dos mesmos. A análise do NDVI da microbacia foi realizada de forma visual, comparando os três anos estudados. O sistema de projeção adotado para todos os mapas gerados foi UTM, datum SAD-69, Zona 21S.

\section{RESULTADOS E DISCUSSÃO}

\subsection{Dinâmica de uso e ocupação do solo}

O mapa de uso e ocupação do solo, para o ano de 1985 apresentou três classes: vegetação florestal, vegetação herbáceo-arbustiva e cultura anual na fase de implantação (Figura 2). No referido ano, a classe corpo d'água não foi identificada na imagem, o que está relacionado à resolução espectral e espacial da imagem Landsat-5/TM, que dificultou a detecção de pequenos corpos hídricos. Outro fator importante é que grande parte dos corpos hídricos estavam encobertos por matas ripárias. No mapa de uso e ocupação do solo dos anos de 1997 e 2011, foi possível distinguir três classes a mais, quando comparado com o ano de 1985, sendo elas: Cultura em fase de crescimento, Vegetação Graminosa e Corpos d'água (Figuras 3 e 4).

O surgimento da classe cultura em crescimento ocorreu devido a intervalos diferenciados de plantio, implicando na necessidade de distinção da plantação em duas classes. Verifica-se que a classe cultura em crescimento nos anos de 1997 e 2011 (Figuras 3 e 4) ocupa áreas que em 1985 foram identificadas como cultura em implantação e vegetação herbáceo-arbustiva. Já a classe vegetação graminosa identificada nos anos de 1997 e 2011 ocupou lugar da vegetação herbáceoarbustiva e a cultura em fase de implantação de 1985 (Figura 2). 


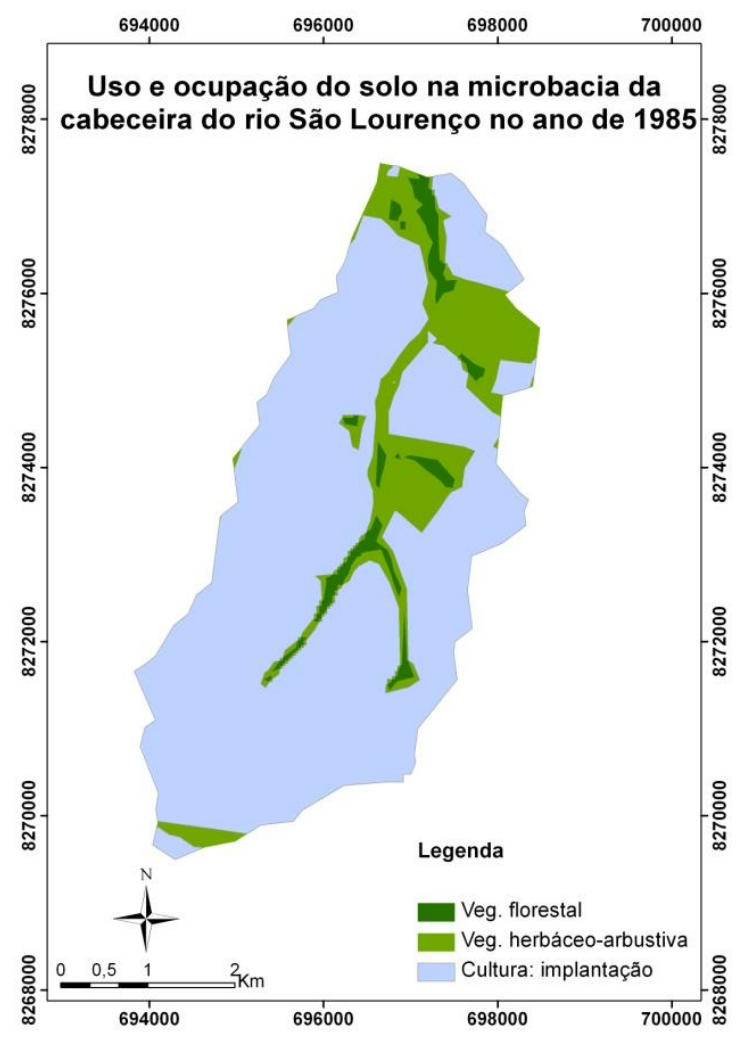

Figura 2: Mapa de uso do solo referente ao ano de 1985.

A discriminação dos corpos d'água, no processo de classificação das imagens, ocorreu devido ao aumento da área inundada ocasionado pelo represamento de corpo hídrico. Na área de estudo, o plantio das culturas agrícolas está sincronizado com o inicio do período das chuvas, que se inicia por volta do mês de Outubro e vai até o mês de Abril. Considerando as datas de obtenção das imagens, grande parte do uso das terras se enquadrou na classe cultura no período de implantação, contemplando $81,54 \%$ da área de estudo (Tabela 2). 
Tabela 2: Área das classes de uso do solo na microbacia da cabeceira do rio São Lourenço.

\begin{tabular}{lccc}
\hline \multicolumn{4}{c}{ Área em km } \\
\multicolumn{1}{c}{ Classes } & Classificação & Classificação & Classificação \\
Veg. Florestal & $\mathbf{1 9 8 5}$ & $\mathbf{1 9 9 7}$ & $\mathbf{2 0 1 1}$ \\
Veg. herbáceo-arbustiva & 0,690 & 1,055 & 1,860 \\
Cultura: implantação & 3,137 & 1,693 & 1,643 \\
Corpos d'água & 16,913 & 9,980 & 8,563 \\
Cultura: crescimento & 0 & 0,080 & 0,090 \\
Veg. Graminosa & 0 & 6,287 & 7,758 \\
Total & 0 & 1,644 & 0,825 \\
\hline
\end{tabular}

Atualmente, a agricultura na área de estudo tende a ocorrer, predominantemente, sob a forma de grandes monoculturas altamente mecanizadas, que representaram a forma mais comum de exploração das terras. Somando a área das classes Cultura no período de implantação e na fase de crescimento, verifica-se que essas ocupavam 81,54\% em 1985, 78,43\% em 1997 e 78,69\% em 2011. As culturas predominantes na região de estudo são: soja, algodão e milho (CAMPO VERDE, 2014, p1).

As classes de maior expressão na microbacia no ano de 1997 foram: cultura no período de implantação $\left(9,980 \mathrm{~km}^{2}\right)$ e cultura na fase de crescimento $\left(6,287 \mathrm{~km}^{2}\right)$ (tabela 02). Nota-se que parte da área do setor Norte e Nordeste da bacia, que em 1985 era ocupada por vegetação herbáceo-arbustiva, foi substituída por vegetação florestal e graminosa em 1997. Em relação à classe Vegetação Florestal, a área aumentou de $0,690 \mathrm{~km}^{2}$ em 1985 para $1,055 \mathrm{~km}^{2}$ em 1997, totalizando um aumento de $52,90 \%$ neste ultimo ano, devido ao plantio de eucalipto em uma pequena área da microbacia, na porção norte e nordeste (Figura 3). 


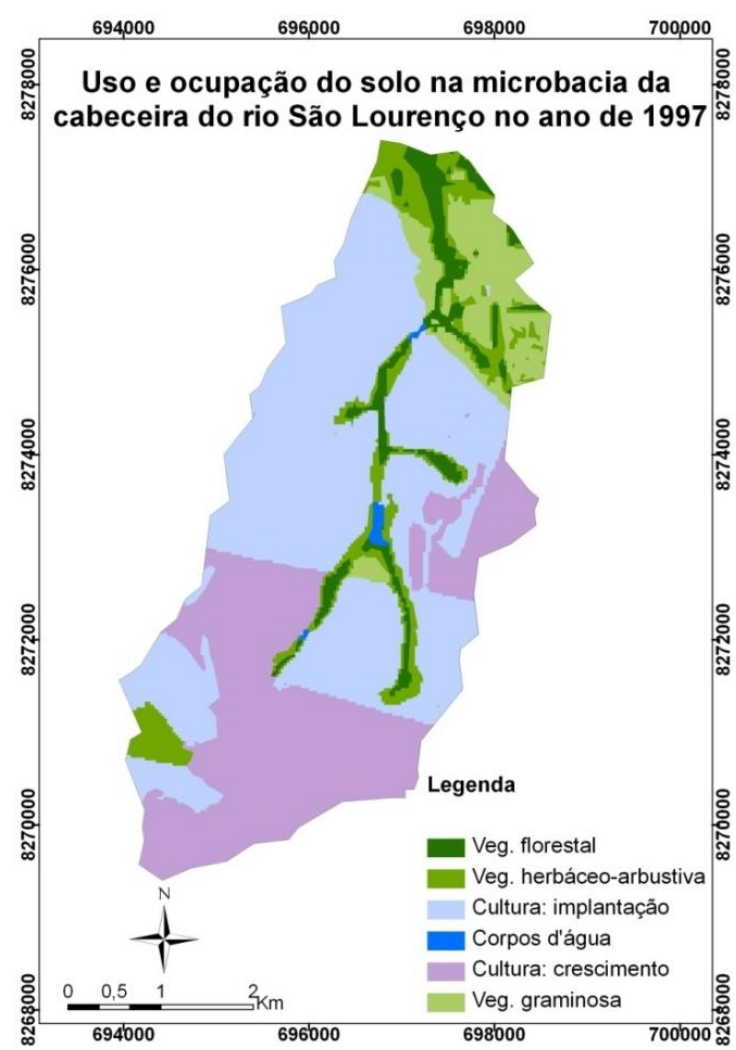

Figura 3: Mapa de uso do solo referente ao ano de 1997.

A agricultura é uma atividade econômica de grande expressão na área de estudo e merece atenção em termos de impactos ambientais negativos, pois, de acordo com Araujo (2005, p.21), além da erosão, as terras cultivadas podem ser degradadas por práticas agrícolas, como a mecanização, que podem levar a compactação e a selagem do solo. Nesse contexto, incluem-se, ainda, o cultivo sucessivo sem períodos de pausas suficientes, a falta de reposição de nutrientes com culturas de cobertura, bem como, o uso excessivo de adubo ou fertilizantes sintéticos, que podem eliminar organismos benéficos do solo, além de serem potencialmente carreáveis para os corpos hídricos.

Malheiros et al. (2012) analisaram a qualidade da água em uma das represas da microbacia estudada e concluíram que a influência antrópica resultante da atividade agrícola, em conjunto com a falta de mata ciliar e a precipitação, resultam em modificações gradativas na qualidade da água da represa, além de contribuir para o assoreamento do ecossistema aquático. 
Impactos em termos de contaminação, proveniente da agropecuária, sobretudo no setor de cabeceiras, como é o caso da nascente do Rio São Lourenço possui ampla magnitude, tendo potencial para atingir regiões distantes como o Pantanal mato-grossense (CALHEIROS et al., 2006, p.3).

Nogueira et al. (2012, p.1482) verificou que em Campo Verde (região Sudeste de MT) e em Lucas do Rio Verde (região Médio-Norte de MT), dois importantes polos agrícolas de Mato Grosso, que existem grandes concentrações de pesticidas nos dois municípios, indicando o risco de contaminação via sistemas hídricos, dentre outras formas. Nascentes circundadas por agricultura, sem faixa de preservação permanente, ficam mais expostas aos defensivos agrícolas, pois a declividade do terreno e o possível excesso de uso de defensivos agrícolas durante a aplicação, somado ao escoamento superficial, favorecem a contaminação do solo, corpos hídricos e biota associada.

Outro fato importante é a contaminação ambiental a partir da volatilização de agrotóxicos usados nos processos agrícolas, que por sua vez precipitam a partir das chuvas, podendo lixiviar e atingir o subsolo e águas subterrâneas, bem como os corpos hídricos superficiais por meio do escoamento superficial com potencial para atingir até mesmo as áreas não cultivadas, causando impactos de difícil mensuração sobre a biota (MOREIRA et al. 2012, p. 1566).

As classes de maior expressão no mapa de uso e ocupação do solo de 2011 (Figura 4) são cultura no período de implantação $(41,28 \%)$ e cultura já na fase de crescimento $(37,41 \%)$. O constante manuseio da terra em culturas temporárias expõe o solo em épocas de preparação, plantio e colheita, implicando em uma série de impactos ambientais negativos, sob a forma de carreamento do solo via vento ou chuva para setores mais baixos (fundos de vale) da microbacia. Isso pode promover assoreamento de corpos hídricos, ou mesmo risco de eutrofização dos mesmos, pois há fertilizantes associados aos sedimentos. Do ponto de vista econômico, uma quantidade expressiva de camada fértil de solo pode ser perdida via os mesmos processos (vento e chuva), o que provocaria sérios prejuízos financeiros aos 
produtores rurais, que terão que repor essa perda, por meio da introdução de fertilizantes sintéticos.

Constatou-se redução da classe vegetação herbáceo-arbustiva de $46 \%$ em 1997 e de 47,62\% em 2011, quando comparado com o ano de 1985. Em 2011 o aumento da classe vegetação florestal ocorreu devido ao plantio de eucalipto, que de maneira geral ocupou parte da área da vegetação herbáceo-arbustiva no setor norte e da vegetação graminosa no setor nordeste, bem como o avanço da agricultura, principalmente na região Centro-Leste da microbacia (Figuras 3 e 4).

Do ponto de vista econômico e ambiental, o plantio de eucalipto fornece matéria prima para fins comerciais, contribuindo de certa forma com a redução do desmatamento da vegetação nativa, desde que ocorra fiscalização com relação ao uso e procedência da madeira a ser utilizada para diversos fins (VITAL, 2007, p.239).

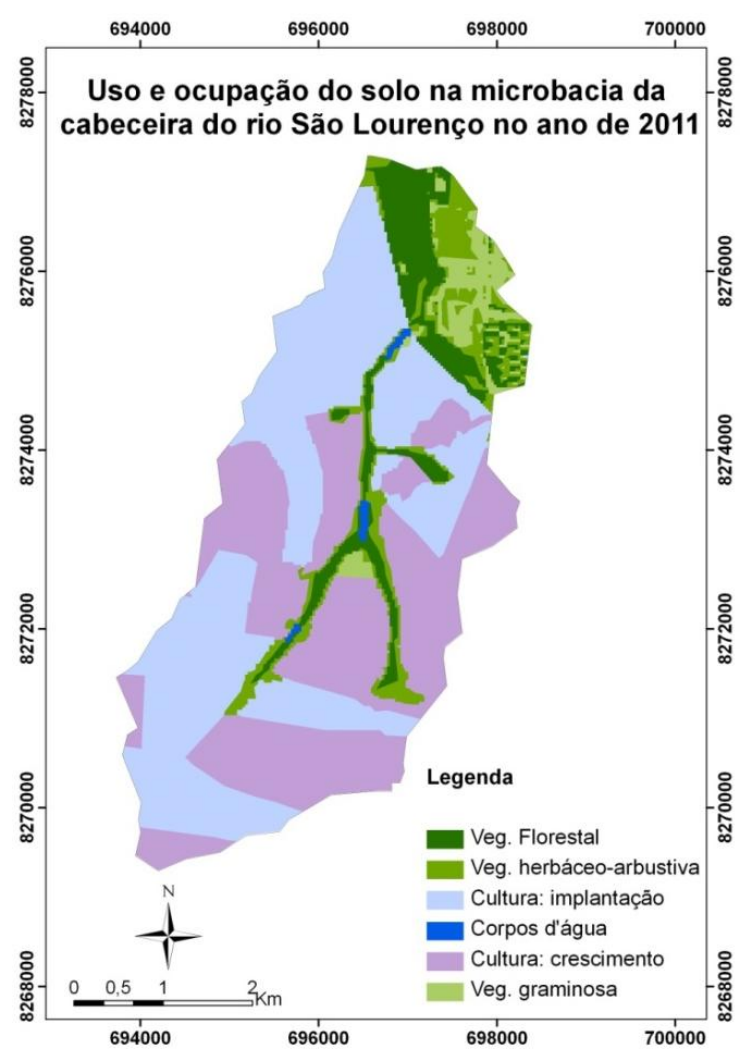

Figura 4: Mapa de uso do solo referente ao ano de 2011. 
O manejo inadequado do eucalipto pode resultar em alto consumo de água, devido ao seu rápido crescimento (ciclo de vida em torno de sete anos), e isso pode ocasionar o rebaixamento do lençol freático causando degradação de áreas de preservação permanente (VITAL, 2007, p.237).

No contexto da paisagem local, a cultura de eucalipto é um elemento da matriz antrópica, que pode fornecer condições para a viabilização de corredores ecológicos, pois, pelo menos em determinados períodos, propiciaria maior permeabilidade para dispersão de fluxo biológico. Porém, é necessário uma compreensão mais adequada acerca desses sistemas agroflorestais, como promotores de maior permeabilidade na paisagem, atuando como possíveis corredores ecológicos (SEOANE et al., 2010, p.213).

O setor de nascentes do Rio São Lourenço é uma área de grande importância econômica e ambiental e o mapeamento histórico de uso e ocupação do solo é estratégica para subsidiar um plano de gestão dos recursos hídricos, bem como dos remanescentes vegetais nativos da região Sudeste de Mato Grosso, que fazem conexão entre Cerrado e Pantanal, por meio da bacia do Rio São Lourenço.

\section{2. Índice de Vegetação por diferença normalizada.}

O Índice de Vegetação por Diferença Normalizada (NDVI) é representado por valores que variam de -1 a 1 e quanto mais próximo de 1, maior será a cobertura vegetal densa e bem desenvolvida (PONZONI; SHIMABUKURO, 2010, p.82). De acordo com Oliveira et al. (2012, p.1829) o NDVI negativo corresponde a maior refletância no visível e refere-se aos corpos d'água, enquanto o NDVI próximo a zero caracteriza-se por refletância similar no visível e infravermelho e refere-se ao solo exposto. O mesmo autor relata que o NDVI maior que 0,3 possui refletância maior no infravermelho e corresponde a vegetação sadia.

O NDVI foi representado por um gradiente de níveis de cinza, sendo que os tons mais escuros representam uma condição de baixo de vigor da vegetação em termos de porte, umidade e densidade, representando ausência de cobertura vegetal de porte florestal. Os tons mais claros representam os maiores valores do 
índice e, portanto, a possível presença de cobertura vegetal de porte florestal, indicando ainda, maior vigor da vegetação. O NDVI da microbacia da cabeceira do rio São Lourenço referente ao mês de outubro de 1985 variou de 0,055 a 1,0 (Figura $5)$.

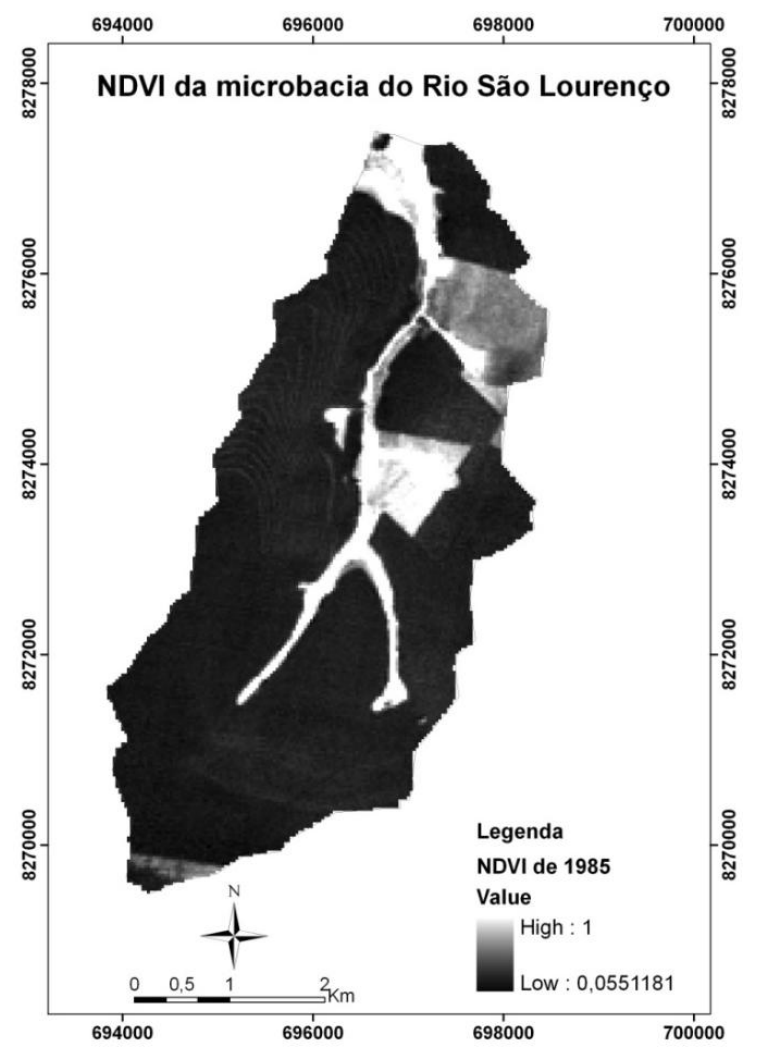

Figura 5: NDVI do setor de cabeceiras do rio São Lourenço referente ao ano de 1985.

Nota-se que o menor valor do NDVI $(0,055)$ ficou próximo a zero. Isso pode ter ocorrido pelo fato do corpo hídrico não aparecer na imagem, pois de acordo com Oliveira et al. (2012, p.1829) a água possui grande refletância da radiação eletromagnética na região do visível e baixa no infravermelho, fazendo com que a mesma fique com valor negativo no cálculo do NDVI. Ponzoni e Shimabukuro (2010, p.79) relatam que as folhas possuem baixa refletância na região do visível, devido à absorção da radiação solar pelos pigmentos fotossintetizantes, mas possuem alta 
refletância do infravermelho próximo, devido ao espalhamento da radiação no interior das folhas em função da estrutura celular.

O NDVI referente ao ano de 1997 variou de $-1,0$ a 0,922 (Figura 6). Na época de obtenção da imagem de satélite (08/10/1997) havia algumas áreas com cultura na fase de crescimento e outras no período de implantação, que foram diferenciadas pelo NDVI. Em relação ao corpo hídrico, na época da coleta da imagem, já havia represas na área de estudo, com isso o NDVI apresentou valor baixo $(-1,0)$, diferenciando do ano de 1985 que não atingiu valor negativo.

Nota-se que algumas áreas agrícolas possuem áreas com índice de vegetação próximo ao da mata ciliar, isso ocorre porque na época das chuvas há um aumento na biomassa verde fazendo com que o NDVI fique mais evidente tanto na floresta quanto na área agrícola causando problema de confusão espectral no período chuvoso (RISSO et al., 2012, p.1323).

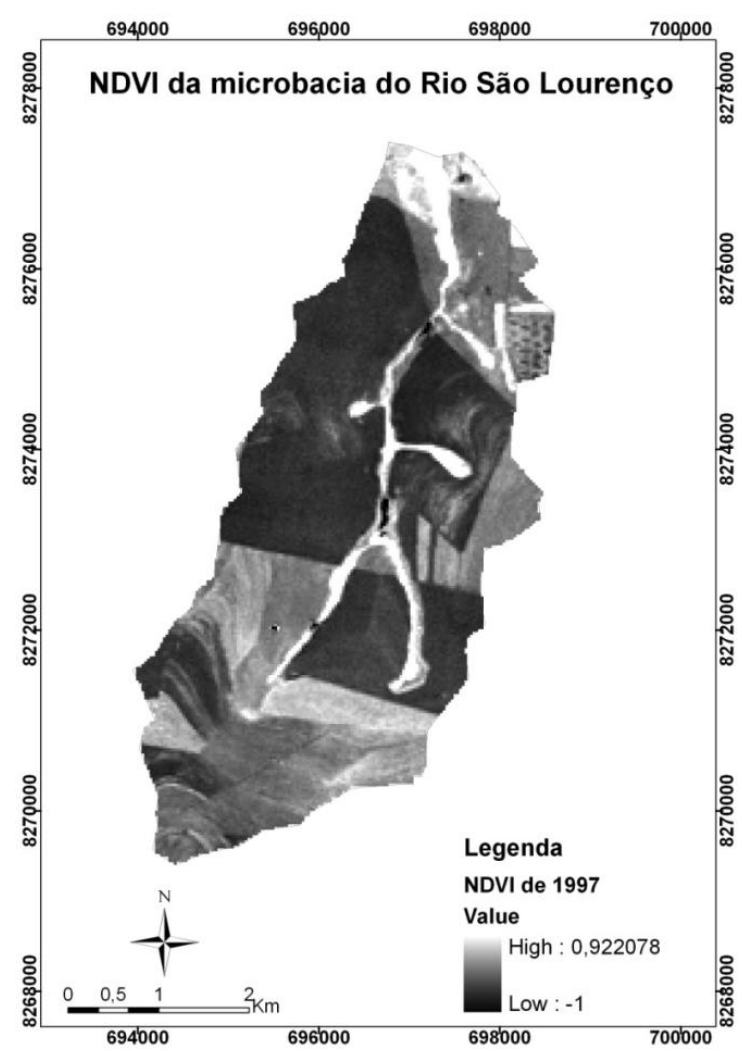

Figura 6: NDVI do setor de cabeceiras do rio São Lourenço referente ao ano de 1997. 
Pacheco et al. (2006, p.66) trabalhou com series temporais de NDVI e constataram um componente sazonal na produção de fitomassa, que ocasionou um decréscimo dos valores de NDVI à medida que avança o déficit hídrico no período da seca.

O NDVI referente ao ano de 2011 apresentou uma variação de $-1,0$ a 1,0 (Figura 7), nesse ano, parte das áreas destinadas à agricultura estava na fase de implantação, e os corpos hídricos, representados por represamentos, ficaram bem definidos.

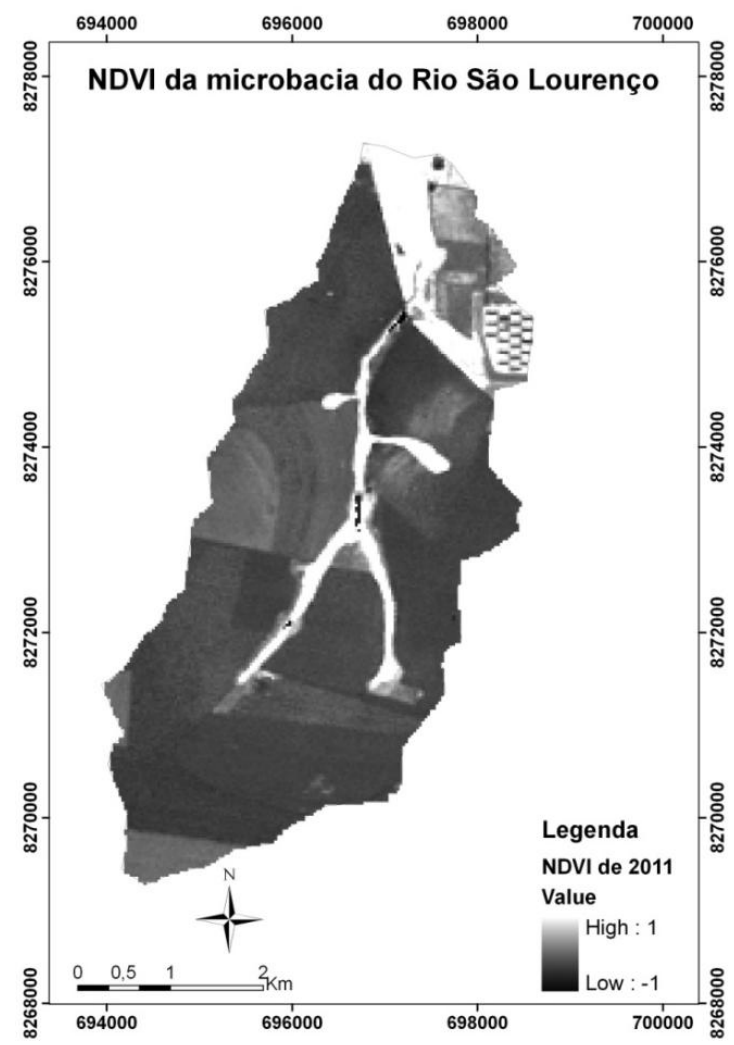

Figura 7: NDVI do setor de cabeceiras do rio São Lourenço referente ao ano de 2011.

Os mapas de NDVI dos três anos analisados calculados para a mesma microbacia apresentam valores positivos acima de 0,3 na mata ciliar, sendo um indicativo da presença de vegetação sadia e vigorosa, quando comparado com a área agrícola e de solo exposto. Isso acontece pelo fato da vegetação ciliar possuir maior quantidade de biomassa vegetal, pois de acordo com Ponzoni; Shimabukuro 
(2010, p.24) quanto maior for a densidade da cobertura vegetal, menor será a refletância na região do visível, devido a maior oferta de pigmentos fotossintetizantes, que por sua vez absorvem a radiação nessa faixa do espectro eletromagnético. A vegetação arbórea (NDVI acima de 0,3) sofreu uma pequena redução no ano de 1997, quando comparado com 1985 e aumentou em 2011, devido à introdução de floresta plantada de eucalipto.

Em dezembro de 2010 foram implantadas na microbacia estudada, algumas unidades demonstrativas de restauração ecológica (UDRE). As UDRE representam um local onde se testam técnicas de regeneração vegetal e geralmente são introduzidas em ambientes impactados. Uma delas está representada na Figura 5. Essa UDRE é parte da dissertação de Checoli (2012, p.45). Sua implantação foi realizada em dezembro de 2010, possuindo uma área de 0,7 hectare, e seu plantio foi realizado com um distribuidor de calcário, sendo que, posteriormente, a muvuca de sementes foi incorporada com uma grade niveladora. A muvuca consiste em uma mistura de diversas sementes de espécies florestais com adubos verdes e substrato (terra ou areia) (CHECOLI, 2012, p.52).

O NDVI de uma das unidades demonstrativas de restauração ecológica (UDRE) foi de 0,370707 em setembro 2011, nove meses após sua implantação. No ano de 1985 o cenário era bem diferente no mesmo local, o solo estava sendo preparado para plantio, o índice ficou em torno de 0,156895 ocasionado pela baixa atividade fotossintética, já no ano de 1997 a cultura já estava estabelecida com alta atividade fotossintética e com isso o índice ficou em torno de 0,375046, praticamente igual ao de 2011 em que a UDRE já estava instalada.

Ao realizar inspeção visual em imagens aéreas de alta resolução obtidas por um Veículo Aéreo Não Tripulado (VANT) da área onde foi implantado uma das UDRE, em dois períodos (Junho de 2011 e Novembro de 2013), verifica-se que no ano de 2011 a área em recuperação possuía maior densidade de vegetação graminosa, apesar de a imagem ser do período seco é possível observar que a área possuía boa cobertura vegetal. Já na imagem de 2013 é possível identificar uma 


\section{DINÂMICA ESPACIAL E TEMPORAL DO USO DO SOLO E ÍNDICE DE VEGETAÇÃO POR DIFERENÇA NORMALIZADA (NDVI) EM SETOR DE CABECEIRA DO RIO SÃO LOURENÇO, CAMPO VERDE, MT}

vegetação de porte herbáceo-arbustiva bem estabelecida, entremeada por árvores (Figura 8).

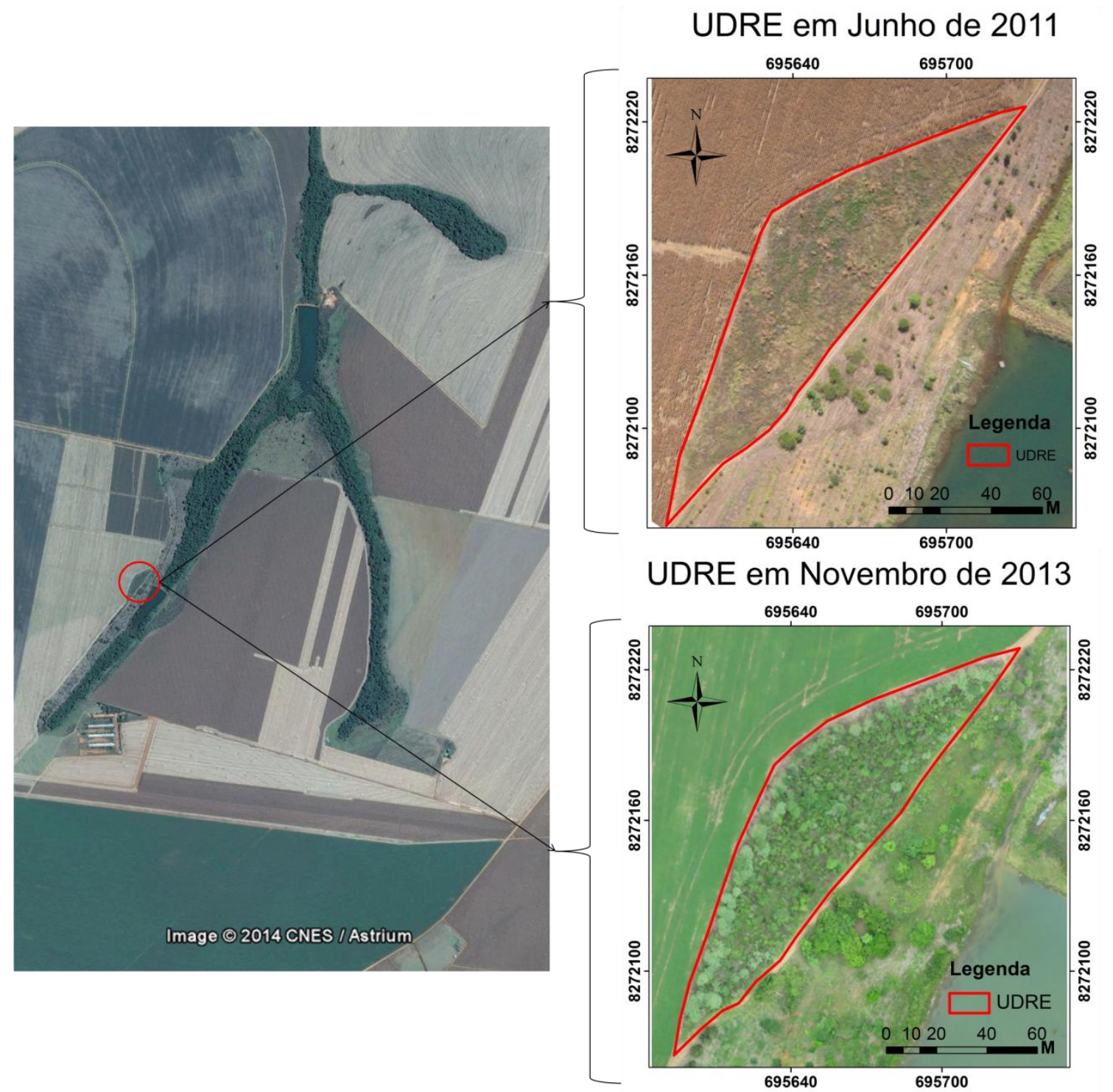

Figura 8: Localização de uma das Unidades Demonstrativa de restauração ecológica

Fonte: Google Earth, 2014 (Imagem CNES/Astrium) e os autores (Imagens aéreas obtidas por VANT). Org. dos autores.

O monitoramento anual dos valores de NDVI, mediante o uso de imagens orbitais ou suborbitais, indicará mudanças na estrutura da cobertura vegetal dessa área em processo de recuperação ambiental. Assim, partindo do princípio que uma 
área degradada, dependendo dos vetores de impactos ali existentes, pode demorar décadas para sua recuperação, a expectativa é que, em havendo manejo adequado do local, o NDVI se eleve no decorrer dos anos, pois de acordo com Checoli (2012, p.60) essa UDRE, foi implantada em dezembro de 2010 e em 2011 apresentou um alto índice de cobertura do solo e elevada riqueza de espécies nativas, evidenciando que a regeneração está acontecendo.

Apesar das imagens Landsat5/TM terem apresentado bons resultados na produção do NDVI, as mesmas possuem resolução espacial de 30 metros, dificultando o monitoramento de pequenas áreas. Há a necessidade de instrumentos que forneçam produtos (imagens) com resolução espacial mais refinada, para que seja possível realizar um monitoramento mais detalhado de pequenas áreas como as UDREs. O uso de imagens multiespectrais de alta resolução espacial, provenientes de sensores embarcados em veículos aéreos não tripulados (VANT), contribuirá de forma significativa para monitoramento dessas UDRE. A partir dessa tecnologia é possível definir, a critério do usuário, a periodicidade, a resolução radiométrica e espectral, bem como a resolução espacial das imagens aéreas, para que se faça o monitoramento da área-alvo.

A partir das imagens aéreas (Figura 8) foi possível acompanhar o desenvolvimento das espécies plantadas na área em recuperação, incluindo uma analise visual do grau de cobertura do solo, além da geração de modelo digital de superfície (MDS), a partir de informações de localização e altitude presentes em sensores acoplados no VANT.

Em termos de mapeamentos de uso e ocupação do solo a partir de imagens aéreas, pesquisas estão sendo desenvolvidas (CÂNDIDO, 2012, p.63) visando encontrar uma rotina de classificação automática que delimite com êxito as diferentes feições presentes em um ecossistema.

\section{CONSIDERAÇÕES FINAIS}

Os resultados do trabalho forneceram subsídios para a elaboração de planos de recuperação de áreas degradadas (PRAD) exigidos pelo órgão ambiental 
estadual, quando se pleiteia o cadastro ambiental rural (CAR) de uma propriedade rural.

A pesquisa está no contexto de um programa de projetos piloto, conduzidos pela Universidade Federal de Mato Grosso, que buscam uma compreensão holística das características ambientais do setor de nascentes do rio São Lourenço, enfocando características químicas do solo e da água e ações de recuperação ambiental, principalmente de áreas de preservação permanente.

A continuidade da pesquisa garantirá suporte para ações de restauração ecológica, que poderá adequar a matriz produtiva presente na área de estudo, para que a mesma seja menos nociva aos ecossistemas naturais remanescentes, tais como áreas de preservação permanente, que são protegidas pela legislação ambiental vigente. Isso, numa escala fina, contribuirá com a adequação ambiental das propriedades rurais situadas na microbacia estudada, e de forma mais geral, fornecerá subsídios para a proteção do patrimônio natural presente nos biomas Cerrado e Pantanal.

\section{AGRADECIMENTOS}

A CAPES, por conceder bolsa de estudos; ao CNPQ pelo apoio financeiro (Processos: 561923/2010-8 e 310724/2011-2); a Universidade Federal de Mato Grosso (UFMT), campus Rondonópolis e Cuiabá (PPG em Recursos Hídricos); e a Prefeitura Municipal de Campo Verde.

\section{REFERÊNCIAS}

ARAUJO, G. H. S.; ALMEIDA, J. R.; GUERRA, A. J. T. Gestão ambiental de áreas degradadas. Rio de Janeiro: Bertrand Brasil, 320p. 2005.

AZEVEDO, A. A.; SAITO, C. H. O perfil do desmatamento em Mato Grosso, após implantação do licenciamento ambiental em propriedades rurais. Cerne, Lavras, v. 19, n. 1, p. 111-122, 2013.

CALHEIROS, D. F.; DORES, E. F. G.; OlIVEIRA, M. D. de. Poluição por pesticidas, nutrientes e material em suspensão nos rios formadores do 
Pantanal Matogrossense. Corumbá: Embrapa Pantanal, 2006. Disponível em: (http://www.cpap.embrapa.br/publicacoes/online/ADM096). Acesso em: 10/04/2013.

CAMPO VERDE. Economia. Campo Verde: Prefeitura Municipal de Campo Verde. Disponível em: (http://www.campoverde.mt.gov.br/public/data/html/informacoes/economia.html). Acesso em 15 de Jan. 2014.

CÂNDIDO, A. K. A. A. Tratamento de imagens orbitais e suborbitais para caracterização ambiental da Cabeceira do Rio São Lourenço-MT. 2012. Dissertação (Mestrado em Engenharia Agrícola) - Instituto de Ciências Agrárias e Tecnológicas, Universidade Federal de Mato Grosso, Rondonópolis, 2012.

CHAVES, A. A. A.; LACERDA, M. P. C.; KATO, E.; GOEDERT, W. J.; RAMOS, M. L. G. Uso das terras da parte norte da bacia do rio Descoberto, Distrito Federal, Brasil. Bragantia, Campinas, v. 69, n.3, p. 711-718, 2010.

CHECOLI, C. H. B. Gestão participativa da microbacia hidrográfica da Cabeceira do Rio São Lourenço: definição e implantação de diferentes tecnologias para realização do PRAD, Campo Verde - MT. 2012. Dissertação (Mestrado em Recursos Hídricos) - Instituto de Ciências Exatas e da Terra, Universidade Federal de Mato Grosso, Cuiabá, 2012.

ESRI. Environmental Systems Research Institute. ArcMap. Vesão 9.3.1, Estados Unidos. CD-ROM. 2010.

FATORELLI, L.; MERTENS, F. Integração de políticas e governança ambiental: o caso do licenciamento rural no Brasil. Ambiente \& Sociedade, Campinas, v.13, n.2, p. 401-415, 2010.

FERNANDES, L. A.; LOPES, P. S. do N.; D'ANGELO, S.; DAYRELL, C. A.; SAMPAIO, R. A.. Relação entre conhecimento local, atributos químicos e físicos do solo e uso das terras. Revista Brasileira de Ciências do Solo, Viçosa, v.32, n.3, p.1355-1365, 2008.

GOOGLE, Earth-Mapas. Imagem CNES/Astrium. 2014. Disponível em: (http://earth.google.com/gallery/index.html). Acesso em: 15/01/2014. 
GOOGLE, $\quad$ Earth-Mapas. $2012 . \quad$ Disponível em: (http://earth.google.com/gallery/index.html). Acesso em: 23/05/2012.

INSTITUTO BRASILEIRO DE GEOGRAFIA E ESTATÍSTICA (IBGE). Ministério do Planejamento, Orçamento e Gestão. Cidades. Disponível em: (http://cidades.ibge.gov.br/xtras/perfil.php?lang=\&codmun=510267\&search=matogrosso|campo-verde|infograficos:-informacoes-completas). Acesso em: 10/01/2014.

INSTITUTO BRASILEIRO DE GeOGRAFIA E ESTATístICA (IBGE). Mapa Político do Brasil com unidades da Federação. Disponível em: (http://downloads.ibge.gov.br/downloads_geociencias.htm). Acesso em: 10/01/2013.

INSTITUTO BRASILEIRO DE GEOGRAFIA E ESTATÍSTICA (IBGE). Mapa de biomas do Brasil. Escala 1:5000000. Rio de Janeiro, 2004. Disponível em: (ftp://geoftp.ibge.gov.br/mapas_tematicos/mapas_murais/biomas.pdf ). Acesso em: 10/01/2014.

KLINK, C. A.; MACHADO, R. B. Conservation of Brazilian Cerrado. Conservation Biology. New York, v. 19, n. 3, p. 707-713, 2005.

LOEBMANN, D. G. dos S. W.; MAÇORANO, R. P.; SILVA, G. B. S. da; VICENTE, L. E.; VICTORIA, D. de C. Interpretação de alvos a partir de imagens de satélite de média resolução espacial. Campinas, SP: Embrapa Monitoramento por Satélite, $2012 . \quad$ Disponível em: (http://www.infoteca.cnptia.embrapa.br/bitstream/doc/961448/1/04812.pdf) Acesso em: 17/02/2014.

MALHEIROS, C. H.; HARDOIM, E. L.; LIMA, Z. M. de; AMORIM, R. S. S. Qualidade da água de uma represa localizada em área agrícola (Campo Verde, MT, Brasil). Ambiente \& Água, Taubaté, v. 7, n. 2, p. 245-262, 2012.

MATO GROSSO. Relatório da ação governamental (RAG): avaliação dos programas - objetivo estratégico 09 (redução do ritmo de desmatamento e recuperação do passivo ambiental e das áreas degradadas dos dos biomas de Mato Grosso). Cuiabá: Governo do Estado de Mato Grosso, 22p. 2009.

MATO GROSSO. Portal Mato Grosso: Geografia do município de Campo Verde. Cuiabá

Disponível

em: 
(http://www.mteseusmunicipios.com.br/NG/conteudo.php?sid=130\&cid=728). Acesso em: 23/10/2012.

MOREIRA, J. C.; PERES, F.; SOMÕES, A. C.; PIGNATI, W. A.; DORES, E. de C.; VIEIRA, S. N.; STRÜSSMANN, C.; MOTT, T. Contaminação de águas superficiais e de chuva por agrotóxicos em uma região do estado do Mato Grosso. Ciência \& Saúde Coletiva, v.17, n6, p. 1557-1568, 2012.

NOGUEIRA, E. N.; DORES, E. F. G. C.; PINTO, A. A.; AMORIM, R. S. S.; RIBEIRO, M. L.; LOURENCETTI, C. Currently used pesticides in water matrices in CentralWestern Brazil. Journal of the Brazilian Chemical Society, São Paulo, v.23, n.8, p. 1476-1487, 2012.

OLIVEIRA, L. C. B. de; GUASSELLI, L. A.; ANTUNES, R. L. dos S. Variação espaço-temporal de NDVI no rio Madeira, na área de aproveitamento hidrelétrico da UHE Santo Antônio - Ro. Revista Geonorte, Manaus, Edição Especial, V.2, N.4, p.1823 - 1832, 2012.

PACHECO, A. P.; FREIRE, N. C. F.; BORGES, Utaiguara da Nóbrega. Uma contribuição do sensoriamento remoto para detecção de áreas degradadas na Caatinga Brasileira. Boletim Goiano de Geografia, Goiânia, v. 26, n. 1, p. 49-68, 2006.

PCl Geomatics. Geolmaging Products and Solutions. Geomatica Versão 9.1 for Windows, Canadá. CD-ROM. 16 de dez. 2003.

PONZONI, F. J.; SHIMABUKURO, Y. E. Sensoriamento remoto no estudo da vegetação. São José dos Campos: Parêntese, 2010.

REIS, A.; BECHARA, F. C.; TRES, D. R. Nucleation in tropical ecological restoration. Scientia Agricola, Piracicaba, v.67, n.2, p.244-250. 2010.

RHOLING, F. J.; SILVA, N. M. da. Padrão de Fragmentação da vegetação nativa na zona rural associada ao perímetro urbano de Rondonópolis, Mato Grosso. Caminhos de Geografia, Uberlândia, v. 13, n. 41, p. 42 - 51, 2012.

RISSO, J.; RIZZI, R.; RUDORFF, B. F. T.; ADAMI, M.; SHIMABUKURO, Y. E.; FORMAGGIO, A. R.; EPIPHANIO, R. D. V. Índices de vegetação Modis aplicados na 
discriminação de áreas de soja. Revista Pesquisa agropecuária brasileira, Brasília, v.47, n.9, p.1317-1326, 2012.

ROUSE, J.W. et al. Monitoring vegetation systems in the Great Plains with ERTS. In: PROCEEDINGS OF THE THIRD ERTS SYMPOSIUM, SP-351 Goddard Space Flight Center, 1973, Washington: NASA, p. 309-317. 1973.

SANTOS, A. R. dos; PELUZIO, T. M. de O.; SAITO, N. S.; SPRING 5.1.2 passo a passo: Aplicações práticas. Alegre- ES: Biblioteca Setorial de Ciencias Agrárias da Universidade Federal do Espirito Santo, 2010. Disponível em: (http://www.mundogeomatica.com.br/Livros/Livro_Spring_5.1.2_Aplicacoes_Praticas/ Livro_SPRING_512_PassoaPasso_Aplica\%C3\%A7\%C3\%A3o_Pr\%C3\%A1tica.pdf). Acesso em: 23/10/2012.

Secretaria de Estado de Meio Ambiente (SEMA). Bases cartográficas Hidrografia. Compartilhamento de informações Geográficas. Disponível em: (http://monitoramento.sema.mt.gov.br/simlam/WindowOpenResizable.aspx?Window Open=MapaDownloadArquivos. asp $\mathrm{x}$ $\mathrm{M}=1^{\star} \mathrm{A}=1$ \&idRetorno=\&acao=). Acesso em: 10/08/2011.

Secretaria de Estado de Meio Ambiente (SEMA). Imagens SPOT de 2007. Rondonópolis. Disponível em: (http://www.sema.mt.gov.br/). Acesso em: 15/05/ 2010.

SEOANE, C. E. S.; DIAZ, V. S.; SANTOS, T. L.; FROUFE, L. C. M. Corredores ecológicos como ferramenta para a desfragmentação de florestas tropicais. Pesquisa Florestal Brasileira, Colombo-PR, v. 30, n. 63, p. 207 - 2016, 2010.

VITAL, M. H. F. Impacto Ambiental de Florestas de Eucalipto. Revista do BNDES, Rio de Janeiro, v. 14, n. 28, p. 235 - 276, 2007. 